\title{
The Psychology of Lying
}

\author{
Anil Thomas \\ NLP Master Practitioner \\ \& \\ Gestalt Therapist \\ Mumbai, India
}

\author{
Nandini Papriwal \\ Sophia Women's College \\ Mumbai, India
}

Lying emerges from the hedonistic nature of humans to avoid pain and to increase pleasure. It can be also seen that we lie not only for personal gains but also for others' gain too. It is a known fact how, telling a lie is costly: emotionally, cognitively, and physiologically. Lie-tellers experience negative emotions, cognitive impairment, physiological stress, and reveal this through nonverbal cues. Systematic detailed information was depicted about types of lying along with providing an overview of convergence and divergence.

\section{Keywords: Lying, Pathological, Deception, Syndrome, Compulsive}

\section{Introduction}

Have you ever seen someone lying and getting away with it? Have you seen an authority figure lying, only to get his job done? Have you lied to your loved ones to protect them? Yes we all indulge in some kind of lying on the daily basis. Lying is a common feature of social interactions among humans. Lying refers to making a false statement to deceive others intentionally, often for some form of personal gain. It has been a part of our everyday life and we have casually normalized this behavioral response in communicating with others. Researches also say that it is a consistent feature of human social behavior. Telling a lie is generally viewed as morally wrong and is psychologically taxing (Gneezy, 2005). Humans lie for various reasons, often to get rid of the situations and escape from the responsibilities. And in order to escape from the consequences of lying, we tend to find possible solutions in the form of lies. An interesting question is do we even know what is a lie and truth? Do we deceive ourselves in order to convince our own ego? Are some people more affected by lying than others? Can lying be categorized as a disorder? Let's explore the answers to all of these questions.

This research was done as a part of an Global Internship Research Program. GIRP is an Umang Foundation Trust initiative to encourage young adults across our globe to showcase their research skills in psychology and to present it in creative content expression.

Editing and reviewing credit : Fiza Rehman

We gratefully acknowledge the support of Mr. Anil Thomas for the mentorship and support.

Correspondence concerning this article should be addressed to

E-mail: office@ijngp

\section{Categories of liars}

There are mainly four broad categories of liars. The Occasional liars are those people who seldom lie, however they are distressed by their actions and feel guilty and tend to seek forgiveness. The occasional liars are not perfect, but are usually respected for their strong attempt at being a truthful person, and humble enough to admit their mistakes.

The Frequent liars are those who go about their life lying every which way and are not concerned about covering their tracks, or making sure their lie makes sense. Everybody around them knows that they are lying because they are sloppy with their lies, and therefore they usually have few friends.

Third type, the smooth liar is just what their description sounds like; this person has become very smooth and skilled at telling lies. These liars are so good with words and body language people tend to believe them even when they know they have a reputation of being a liar. Fourth type the compulsive liar lies when they don't have to, even if telling the truth makes more sense than the lies they tell. These people have an addiction to lying, and they simply cannot stop and they tend to spend hours studying situations trying to come up with more lies that will allow them to maintain all their previous lies. Pathological liars tell compulsive lies without a clear motive. This type of lying is different from nonpathological lying, where the lie is often beneficial in some way.

\section{What is the science behind compulsive lying?}

Psychologists who are studying how and why children learn to lie are finding that certain lies play positive roles in a child's emotional development. A child's first successful lie, for instance, is seen by some researchers as a positive milestone in mental growth. Psychiatrists see lying as pathological when it is so persistent as to be 
destructive to the liar's life, or to those to whom he lies. So are we raising our children right away? It has been stated that the more you do it, the easier it gets.

Compulsive lying describes a condition in which a person tells falsehoods out of habit, sometimes for no reason at all. It is also known as pathological lying, mythomania, and habitual lying. Psychiatrists see lying as pathological when it is so persistent as to be destructive to the liar's life, or to those to whom he lies. The most blatant lying is found in the condition called "pseudologia fantastica," in which a person concocts a stream of fictitious tales about his past, many with a small kernel of truth, all self-aggrandizing. Research suggests that this most extreme form of lying is associated with a specific neurological pattern: a minor memory deficit combined with impairment in the frontal lobes, which critically evaluate information. In such cases, the person suffers from the inability to assess the accuracy of what he says, and so can tell lies as though they were true.

The DSM-5 mentions that deception is a symptom of antisocial personality disorder and is used for external incentive. Furthermore, PL behaviour involves telling lies without a specific reason, and their lies grow from an initial lie. The subsequent growth of lies, however, tends to cause more distress. Thus, PL contains elements of compulsiveness. A University of Southern California study has found the first proof of structural brain abnormalities in people who habitually lie, cheat and manipulate others. While previous research has shown that there is heightened activity in the prefrontal cortex the area of the brain that enables most people to feel remorse or learn moral behaviour - when normal people lie, this is the first study to provide evidence of structural differences in that area among pathological liars.

Electrical stimulation of the prefrontal cortex appears to improve our ability to deceive. This region of the brain may, among other things, be responsible for the decision to lie or tell the truth. It is not only humans who practice deception. Trickery and deceit of various kinds have also been observed in higher mammals, especially primates. The neocortex - the part of the brain that evolved most recently - is critical to this ability. In our own kind, small children love to make up stories, but they generally tell their first purposeful lies at about age four or five. Before starting their careers as con artists, children must first acquire two important cognitive skills. One is deontic reasoning: the ability to recognize and understand social rules and what happens when the rules are transgressed. For instance, if you confess, you may be punished; if you lie, you might get away with it. The other is theory of mind: the ability to imagine what another person is thinking. I need to realize that my mother will not believe that the dog snagged the last burger if she saw me scarf down the food. As a step to developing a theory of mind, children also need to perceive that they know some things their parents do not, and vice versa-an awareness usually acquired by age three or four.

\section{Categories of lying that may overlap with each other:}

Pathological lying is a possible symptom of certain personality disorders, emerging from narcissistic personality disorder, and borderline personality disorder. According to a recent study it has revealed that $13 \%$ of people believe themselves to be pathological liars or are deemed so by people in their social circle. These people reportedly tell almost 10 lies every day. People suffering from NPD are prone to indulge in activities where they receive immense importance and they have a certain need for admiration and special treatment. They are great at lying because of a complete lack of empathy for others. A person with BPD or NPD may lie to distort reality into something that fits with the emotions that they are feeling, rather than the facts. American psychologist, Martha Stout stated in an interview that Pathological liars lie just to see if they can treat people.

Malingering is deliberate lying where the person grossly exaggerates or totally lies about physical and/or psychological symptoms. Unlike "archetypal" pathological liars, malingerers are typically motivated to tell lies for a specific purpose such as to obtain financial compensation, to avoid working, to avoid military service, to avoid criminal prosecution, etc.

Gansers syndrome is a rare dissociative disorder (only 101 recorded cases ever) characterized by affected people giving nonsensical answers to questions (and goes under many other names including "nonsense syndrome" and "balderdash syndrome"). Unlike the elaborate and sometimes fantastical stories told by archetypal pathological liars, the lies told by those with GS are very simplistic and approximate.

\section{Self-deception}

It's profoundly said that "never argue with someone who believes their own lies" Is there any truth to this saying? Let's find out. Self-deception isn't just lying or faking, but is deeper and more complicated, says Del Paulhus, psychology professor at University of British Columbia and author of a widely used scale to measure selfdeceptive tendencies. It involves strong psychological forces that keep us from acknowledging a threatening truth about ourselves, he says. Many people deceive themselves to avoid making difficult changes. For some people, self-deception becomes a habit, spinning out of control and providing a basis for more lies. In research co-written by Dr. Norton and published last year in Proceedings of the National Academy of Science, college students who were given an answer key to an intelligence test, allowing them to cheat, scored higher than a control group. They later predicted, however, that they also would score higher on a second test without being allowed to cheat. They were "deceiving themselves into believing their strong performance was a reflection of their ability," the study says. Many people have a way of "fooling their inner eye" to believe they are more 
successful or attractive than they really are, Dr. Trivers says. When people are asked to choose the most accurate photo of themselves from an array of images that are either accurate, or altered to make them look up to $50 \%$ more or less attractive, most choose the photo that looks $20 \%$ better than reality, research shows. Researchers disagree over what exactly happens in the brain during self-deception. Social psychologists say people deceive themselves in an unconscious effort to boost self-esteem or feel better. Evolutionary psychologists, who say different parts of the brain can harbor conflicting beliefs at the same time, say self-deception is a way of fooling others to our own advantage.

\section{What are the cues of deception?}

Researchers have examined verbal communication cues of deception. Speech cues such as pauses, voice pitch; interruptions, hesitations, latency to respond, and response length have been used to detect deception (Vrij, 1995; Vrij, Edward, \& Bull, 2001; Vrij, Edward, Roberts, \& Bull, 2000). The contents of speech such as descriptions of feelings, reproductions of speech, amount of detail, logical inconsistencies, and spontaneous corrections have also been found to vary with the veracity of statements (DePaulo, Lindsay, Malone, Muhlenbruck, Charlton, and Cooper, 2003; Vrij, Edward, Roberts, \& Bull, 2000). The cognitive hypothesis focuses on the mental workload of deception and proposes that lying requires more cognitive effort which detracts from the liar's ability to behave normally.

\section{Political lies}

"A lie gets halfway around the world, before the truth has a chance to get its pants on" says Winston Churchill. Why do we trust things so easily and believe it especially when it comes from a person who holds the power? Why do lies have a tendency to spread like a wildfire, and truth is always doubted? Various researchers explain this phenomena and reason behind this human behavior. Truth is sometimes hard to fathom and accept.

Lying and deception have always been considered perennials of politics (Robinson et al., 2018). In recent decades, western democracies have been hit by cynicism that is instigated by increased widespread poorly challenged political lies and scandals. Politicians lie and deceive for many reasons, whether it is in the public interest or their personal interest. However, an interesting question here is, why do people vote for politicians they know are liars? In other words, in the current post-truth era that is occupied by public cynicism about politics, how voters overcome such cynicism, and yet still turnout and maintain some degree of political efficacy. An example of this phenomenon, Boris Johnson who has a long history of systematic lying, yet he won a landslide victory in the 2019 General Elections. He became the UK Prime Minister and the one responsible for delivering Brexit. Lying proved a very successful strategy for political causes and individual candidates in the U.K. and U.S. elections in 2016, leading Oxford Dictionaries to choose "post-truth" as its 2016 word of the year.
Picciotto (2019) argues that this phenomenon is a clear example of the post-truth era we currently live in, an era that is characterised by the denial of facts and tolerance of politicians' lies and deception.In a representative democracy, politicians and voters enter into a principalagent relationship; in which the voters' rationale to select candidates is based on their perceived trustworthiness. Swire et al. (2017) approached the phenomenon from a cognitive perspective. Their focus was on source credibility, where individuals do not have enough time and cognitive resources to comprehend the complexity of politics. Therefore, they may use the perceived credibility of politicians as a heuristic to motivate their evaluation of what is true or what is a lie. Hahl et al. as well carried out a survey post-2016 US Presidential Elections to investigate how a constituency of voters can find a candidate "authentically appealing" even though he is a "lying demagogue". Their experimental analysis provides an explanation of how a lying politician may be viewed as more authentic than another politician who neither lies nor blatantly violates publicly endorsed norms. He found out that a political candidate can gain a perception of authenticity in two ways; via sincerity or via authentic champion hood. When "trustworthiness" becomes the most dominant explanation for why people vote for a particular candidate and participate in the political game, lies and deception become irrelevant and widely forgiven and ignored. Famous political lies in the history include:

On June 8th, 1967, during the Six-Day War between Israel, Jordan, Syria and Egypt, the Israeli Air Force attacked an American spy ship, the USS Liberty. While Israel apologized and claimed they' $d$ mistaken it for an Egyptian ship, analysts suggest the attack was planned to force the U.S. to join the war by blaming the Egyptians, and that the entire thing was covered up by the Israeli and U.S. governments.

Another famous one is when the last words spoken by President Richard Nixon, when he denied any involvement in the June 17th, 1972 break-in at the Democratic National Committee headquarters at the Watergate Hotel. However, the resulting investigation found proof that the Nixon administration had spied on the Democrats' campaign, forcing Nixon to become the first and only U.S. president to resign the office.

\section{Casual lies}

People tell everyday lies to try to make themselves look better or feel better, to protect themselves from embarrassment or disapproval or from having their feelings hurt, and to try to gain the esteem and affection of other people. Although people tell many lies about their achievements and their failures, their actions, plans, and whereabouts, and the reasons for their actions or inactions, the lies that they told most often were about their feelings. When people told other-oriented lies, they often pretended to feel more positively than they really did feel, and they often claimed to agree with other people when in fact they disagreed. In short, in everyday life, people lie about what they are really like and how 
they really do feel.

When gaslighters /narcissists are caught, they go on the attack. They will mostly blame it on the environment. They may also choose to continue lying without compunction, and run away from apologizing, as they see apology as the sign of weakness. Researchers predicted that people will lie less often in close relationships than in casual ones. Also, because lie telling violates close relationship ideals such as openness and authenticity, we predicted that when people do lie to their close relationship partners, they will feel more distressed than when they lie to partners in casual relationships (Miller, Mongeau, \& Sleight, 1986).

One way that people might try to communicate their love and concern for the important people in their lives is by telling altruistic lies. They compliment them, pretend to agree with them, and claim to understand. The metamessages of these lies may be supportive rather than threatening (cf. Ruesch \& Bateson, 1951; Watzlawick, Beavin, \& Jackson, 1967). The study found, "dishonesty escalated over time when it was self-serving, showing that the simple act of repeated dishonesty by itself is not enough for escalation to take place..." Essentially, if we are going to tell a lie and stick to it even when it starts spiraling out of control, " - a self-benefiting motivation must also be present." secrets and lies kill relationships, no matter how careful you are, you will get caught.

\section{How to know if someone is lying?}

Someone telling a lie often gives clues that what's being said is not true. The clues may be body language, facial expressions or what the person actually says. Someone telling a fib often perspires or seems nervous and jittery. Lack of eye contact or wandering eyes while telling a tale tops the list of how to tell if someone is lying. Liars will talk with a rise in the pitch of the voice. It is quite important for a person to use intuition or experience when they see something suspect. If someone is blinking a lot (sign of pressure) when you are asking them a hard hitting question, they should be able to determine where the pressure is coming from. Is the conversation/context making them anxious or are they actually hiding information? Gestures that become pronounced during the telling of a lie begin with rubbing the forehead, licking the lips, swallowing often and hard, and wringing hands. If they are lying there tends to be much more of these than necessary because people tend to be very good at coming up with detailed lies.

\section{Conclusion}

As we have established that lying is a part of our daily and social life, however it is important to understand why some people develop a habit of lying. Lying can also be explained from the viewpoint from Maslow's hierarchy of need. According to his theory we have an innate tendency to move towards achieving our needs one after the other. In order to achieve these levels and to prevent the obstacles from coming way to our need satisfaction we make statements which may be not true. Researches see lying as pathological when it is so persistent as to be destructive to the liar's life, or to those to whom he lies. We lie so casually that sometimes we deceive ourselves. Politicians have always been seen lying in their speech about their political agendas, about themselves and the policies that would wish to frame. As a matter of fact, we still choose to vote for them, can this be a form of self deception? It is a phenomenon that is worth thinking about --- are we really trusting our own instincts? Is this a larger game played by our politicians to have control over us? It's interesting how we are surrounded by deception, and the real question is do we know the truth of anything? But always remember

"A lie has speed, but truth has endurance"

-Edgar J. Mohn.

\section{References}

Vrij, A. (1995). Behavioral correlates of deception in a simulated police interview. Journal of Psychology: Interdisciplinary and Applied, 129(1), 15-28.

DePaulo, B. M., Lindsay, J. J., Malone, B. E., Muhlenbruck, L., Charlton, K., \& Cooper, H. (2003). Cues to deception. Psychological Bulletin, 129(1), 74118

Miller, G.R., Mongean, P.A., \& Sleight, C. (1986). Fudging with friends and lying with lovers: Deceptive communication in personal relationships. Journal of Social and Personal Relationships, 3, 495- 512.

Ruesch, J., \& Bateson, G. (1951). Communication: The social matrix of psychiatry. New York: Norton.

Watzlawick, P., Beavin, J. H., \& Jackson, D. D. (1967). Pragmatics of human communication: A study of interactional patterns, pathologies, and paradoxes. New York: Norton.

Gunderman, R., \& Kane, L. (2015, July 22). A Study in Deception: Psychology's Sickness. The Atlantic. https://www.theatlantic.com/health/archive/2013/04/astudy-in-deception-psychologys-sickness/274739/

Wan, W. S. K. (2018, August 24). Why liars lie: What science tells us about deception. Washington Post. https://www.washingtonpost.com/news/speaking-ofscience/wp/2018/08/24/why-liars-lie-what-science-tellsus-about-false-statements/

Gneezy, U. (2005). Deception: The role of consequences. The American Economic Review, 95, 384 -394. http://dx.doi.org/10.1257/000282 8053828662 
The Psychology of Lying 